\title{
Cannot Be Assessed
}

National Cancer Institute

\section{Source}

National Cancer Institute. Cannot Be Assessed. NCI Thesaurus. Code C48657.

Aspects of the context prevent the evaluation needed to determine a value. 